\title{
High-flow oxygen therapy for extubation failure prevention in high-risk critically ill patients: a randomized multicenter trial
}

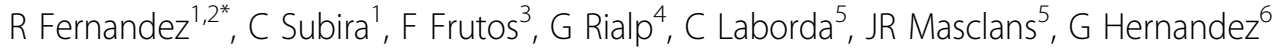 \\ From ESICM LIVES 2015 \\ Berlin, Germany. 3-7 October 2015
}

\section{Introduction}

Extubation failure in critically ill patients has associated morbidity, but it cannot be safely predicted or avoided. Preventive NIMV has proved beneficial only in hypercapnic patients. We hypothesized that High-flow oxygen therapy may reduce postextubation respiratory failure due to gas humidification, avoidance of lung collapse by moderate PEEP, and work of breathing reduction by dead-space washing.

\section{Objectives}

Our objective was to reduce postextubation respiratory failure with High-flow in high-risk patients.

\section{Methods}

Randomized multicenter trial in patients who successfully passed a spontaneous breathing trial. Only patients with criteria for high-risk of failure were randomized to receive conventional oxygen or High-flow oxygen (Optiflow ${ }^{\circledR}$ : Fisher Paykel) for 24 hours post-extubation. Primary outcome was respiratory failure within 72 hours postextubation. Secondary outcome were: reintubation, ICU and hospital length of stay, and survival. Statistical analysis included multiple logistic regression models.

\section{Results}

The study was stopped after 18 months due to low recruitment. We enrolled 155 patients: 77 with conventional and 78 with High-flow oxygen. Groups were very similar at enrollment. All patients tolerated the High-flow system. We found the projected reduction in postextubation respiratory failure $(20.5 \%$ vs. $27.3 \%, p=0.3)$ that failed to reach statistical significance due to sample size. Similarly, the benefit in reintubation $(16.7 \%$ vs. $19.5 \%, \mathrm{p}=0.6)$ didn $^{\prime}$ $t$ reach significance. We found no differences in ICU length of stay, hospital length of stay, and survival. By a logistic regression model, we were able to independently associate high-flow with reduction in postextubation respiratory failure (OR $0.4 \mathrm{p}=0.049)$, by including COPD, cancer, length of MV, obesity, and cardiac failure in the model.

\section{Conclusions}

High-flow oxygen therapy for 24-h may reduce postextubation respiratory failure in high-risk critically ill patients.

\section{Authors' details}

${ }^{1}$ Hospital Sant Joan de Deu / Fundacio Althaia, Manresa, Spain. ${ }^{2}$ Universitat Internacional de Catalunya. CIBERES, Barcelona, Spain. ${ }^{3} \mathrm{H}$. Universitario de Getafe, Madrid, Spain. ${ }^{4}$ H. Son Llatzer, Mallorca, Spain. ${ }^{5} H$. U. Valle Hebron, Barcelona, Spain. ${ }^{6} \mathrm{H}$. Virgen de la Salud, Toledo, Spain.

Published: 1 October 2015

doi:10.1186/2197-425X-3-S1-A164

Cite this article as: Fernandez et al:: High-flow oxygen therapy for extubation failure prevention in high-risk critically ill patients: a randomized multicenter trial. Intensive Care Medicine Experimental 2015 3(Suppl 1):A164. 